\title{
PENGARUH KUALITAS PELAYANAN, FASILITAS, KEPERCAYAAN DAN PROMOSI TERHADAP KEPUASAN PELANGGAN (Studi Pada Pelanggan Hotel Pandanaran Semarang)
}

\author{
Maulida Putri Andari ${ }^{1}$ \\ Edy Mulyantomo ${ }^{2}$ \\ maulidaputriandari@gmail.com ${ }^{1}$ \\ Fakultas Ekonomi Universitas Semarang \\ Diterima: Mei 2020, Disetujui: Juni 2020, Dipublikasikan: Juli 2020
}

\begin{abstract}
The purpose of this study was to determine the effect of service quality, facility, trust and promotion to the customer satisfaction due to a decreasing customer satisfaction of Pandanaran Hotel Semarang. This research is quantitative approach.

The population is all customers of the Pandanaran Hotel Semarang that were not known for certain, meanwhile the sampling technique used was a non probability sampling then was done by the method of purposive sampling the number of those are

96 respondents and the analysis tool used in this study was multiple linear regression.

The results showed that service quality, facility, trust and promotion variables had a positive and significant effect on customer satisfaction in Pandanaran Hotel Semarang and the adjusted $R$ square value in the regression model was obtained amounting to 0.668 which means that 66.8 percent of customer satisfaction variables can be explained by service quality, facility, trust and promotion variable while the remaining 33,2 percent is explained by other variables outside of this study.

Keywords: service quality, facility, trust and promotion and customer satisfaction
\end{abstract}

\section{ABSTRAK}

Tujuan penelitian ini adalah untuk mengetahui pengaruh kualitas pelayanan, fasilitas, kepercayaan dan promosi terhadap kepuasan konsumen akibat penurunan kepuasan konsumen Pandanaran Hotel Semarang. Penelitian ini menggunakan pendekatan kuantitatif.

Populasinya adalah seluruh pelanggan Hotel Pandanaran Semarang yang tidak diketahui secara pasti, sedangkan teknik pengambilan sampel yang digunakan adalah non probability sampling kemudian dilakukan dengan metode purposive sampling yang jumlahnya adalah 96 responden dan alat analisis yang digunakan dalam penelitian ini adalah regresi linier berganda.

Hasil penelitian menunjukkan bahwa variabel kualitas pelayanan, fasilitas, kepercayaan dan promosi berpengaruh positif dan signifikan terhadap kepuasan pelanggan di Pandanaran Hotel Semarang dan diperoleh nilai adjusted $\mathrm{R}$ square pada model regresi sebesar 0,668 yang berarti 66,8 persen variabel kepuasan pelanggan. dapat dijelaskan oleh variabel kualitas pelayanan, fasilitas, kepercayaan dan promosi sedangkan sisanya 33,2 persen dijelaskan oleh variabel lain di luar penelitian ini.

Kata kunci: kualitas layanan, fasilitas, kepercayaan dan promosi, dan kepuasan pelanggan

\section{PENDAHULUAN}

Industri pariwisata yang bergerak di bidang akomodasi perhotelan di era global ini sangatlah ketat dalam pembangunan maupun persaingan. Semakin banyak 
bangunan perhotelan di berbagai tempat, baik yang sudah berdiri maupun yang akan dibangun. Hal ini menandakan persaingan tidak hanya terjadi dalam dunia bisnis perdagangan, persaingan ini pun juga terjadi pada setiap instansi yang menyediakan jasa, dimana mereka berlomba untuk memberikan yang terbaik agar dapat memberikam kepuasan bagi instansi dan masyarakat yang memakai jasa ataupun pelayanan.

Dalam penelitian ini mengambil data jumlah keluhan pelanggan pada Hotel Pandanaran Semarang terletak di jalan Pandanaran No 58 Semarang,

Tabel 1

Jenis dan Jumlah Keluhan Pelanggan Hotel Pandanaran Semarang (2016-2018)

\begin{tabular}{|c|c|c|c|c|}
\hline \multirow[b]{2}{*}{ NO } & \multirow{2}{*}{$\begin{array}{c}\text { JENIS KELUHAN } \\
\text { PELANGGAN } \\
\end{array}$} & \multicolumn{3}{|c|}{ JUMLAH KELUHAN (ORANG) } \\
\hline & & 2016 & 2017 & 2018 \\
\hline 1 & Kebersihan kamar hotel & 12 & 34 & 34 \\
\hline 2 & Fasilitas kamar hotel & 42 & 26 & 42 \\
\hline 3 & Menu makanan dan minuman & 22 & 24 & 14 \\
\hline 4 & $\begin{array}{l}\text { Pelayanan dan ketrampilan dalam } \\
\text { bertugas }\end{array}$ & 8 & 20 & 36 \\
\hline & JUMLAH & 84 & 104 & 126 \\
\hline
\end{tabular}

Sumber: Hotel Pandanaran

Semarang,2019

Berdasarkan data tersebut menunjukkan jumlah keluhan pelanggan Hotel Pandanaran Semarang mengalami kenaikan setiap tahunnya, hal ini mengindikasikan adanya penurunan kepuasan pelanggan pada Hotel Pandanaran Semarang, berdasarkan data tersebut menjadikan ketertarikan untuk meneliti tentang kepuasan pelanggan Hotel Pandanaran Semarang. 


\section{KERANGKA PEMIKIRAN TEORITIS DAN PERUMUSAN HIPOTESIS}

\section{Kepuasan Pelanggan}

Menurut Kolter (1997) arti dari kepuasan pelanggan yaitu tingkat perasaan seseorang setelah membandingkan performansi (atau hasil) yang dirasakan dibandingkan dengan harapannya. Untuk dapat melakukan sesuatu yang bernilai lebih, tidak cukup hanya dengan sekedar memberikan layanan, melainkan harus bisa memberikan kepuasan pada pelanggan.

\section{Kualitas Pelayanan}

Parasuraman (2001:165) menyatakan bahwa kualitas pelayanan adalah suatu pengertian yang kompleks tentang mutu dan tentang memuaskan atau tidak memuaskan, kualitas pelayanan dikatakan bermutu apabila pelayanan yang diharapkan lebih kecil daripada pelayanan yang dirasakan (bermutu), dikatakan konsep kualitas layanan memenuhi harapan, apabila pelayanan yang diharapkan sama dengan yang dirasakan (memuaskan), demikian pula dikatakan persepsi tidak memenuhi harapan apabila pelayanan yang diharapkan lebih besar daripada pelayanan yang dirasakan (tidak bermutu).

\section{Fasilitas}

Fasilitas adalah sumber daya fisik yang harus ada sebelum suatu jasa dapat ditawarkan kepada pelanggan (Lupioadi, 2006). Kotler (2001) menyatakan bahwa salah satu upaya yang dilakukan manajemen perusahaan terutama yang berhubungan langsung dengan kepuasan pelanggan yaitu dengan memberikan fasilitas sebaik-baiknya demi menarik dan mempertahankan pelanggan.

\section{Kepercayaan}

Moorman (1993) mendefinisikan kepercayaan (trust) sebagai kesediaan (willingness) individu untuk menggantungkan dirinya pada pihak lain yang terlibat dalam pertukaran karena individu mempunyai keyakinan (confidence) kepada pihak lain. Kepercayaan ada jika para pelanggan percaya bahwa penyedia layanan jasa tersebut dapat dipercaya dan juga mempunyai derajat integritas yang tinggi (Karsono,2006:124). 


\section{Promosi}

Menurut Stanson dalam Angipora (1999) promosi adalah kombinasi strategi yang paling baik dari variabel-variabel periklanan, penjualan personal dan alat promosi yang lain, yang semuanya direncanakan untuk mencapai tujuan program penjualan.

\section{Pengaruh Kualitas Pelayanan Terhadap Kepuasan Pelanggan}

Jasa yang unggul (Service Excellence) adalah salah satu sikap atau cara karyawan dalam melayani pelanggan secara memuaskan (Tjiptono, 2005). Hasil penelitian Eka Kesuma (2015), Aryo Prasetyo (2015), Anissa Faradina (2016) pada pengujian regresi linier berganda menghasilkan bahwa variabel kualitas pelayanan memiliki pengaruh positif serta pada uji hipotesis juga memiliki pengaruh yang signifikan terhadap kepuasan pelanggan. Berdasarkan uraian diatas, maka hipotesis yang dapat diambil dalam penelitian ini adalah,

H1: Kualitas pelayanan berpengaruh positif terhadap kepuasan pelanggan.

\section{Pengaruh Fasilitas Terhadap Kepuasan Pelanggan}

Kotler (2001) menyatakan bahwa salah satu upaya yang dilakukan manajemen perusahaan terutama yang berhubungan langsung dengan kepuasan pelanggan yaitu dengan memberikan fasilitas sebaik-baiknya. Hasil penelitian Aryo Prasetyo (2015) pada pengujian regresi linier berganda menghasilkan bahwa variabel fasilitas memiliki pengaruh positif serta pada uji hipotesis juga memiliki pengaruh yang signifikan terhadap kepuasan pelanggan. Berdasarkan uraian diatas, maka hipotesis yang dapat diambil dalam penelitian ini adalah,

H2: Fasilitas berpengaruh positif terhadap kepuasan pelanggan.

\section{Pengaruh Kepercayaan Terhadap Kepuasan Pelanggan}

Apabila perusahaan telah mampu memberikan apa yang pelanggan harapkan dan inginkan maka akan timbul trust (kepercayaan) dari pelanggan dimana salah satu indikasi bahwa adanya kepercayaan dari konsumen adalah melakukan pembelian kembali terhadap produk tersebut. (Jasfar, 2002). Semakin tinggi rasa kepercayaan yang di rasakan pelanggan maka semakin tinggi kepuasan yang di dapat (Ball dan Machas, 
2004). Hasil penelitian Eka Kesuma (2015), Aryo Prasetyo (2015), Anissa Faradina (2016) pada pengujian regresi linier berganda menghasilkan bahwa variabel kualitas pelayanan memiliki pengaruh positif serta pada uji hipotesis juga memiliki pengaruh yang signifikan terhadap kepuasan pelanggan. Berdasarkan uraian diatas, maka hipotesis yang dapat diambil dalam penelitian ini adalah,

H3: Kepercayaan berpengaruh positif terhadap kepuasan pelanggan.

\section{Pengaruh Promosi Terhadap Kepuasan Pelanggan}

Menurut Tjiptono (2006), "Promosi adalah suatu bentuk komunikasi pemasaran dimana aktivitas pemasaran berusaha menyebarkan informasi, mempengaruhi atau membujuk, mengingatkan pasar sasaran atas perusahaan dan produknya agar bersedia menerima, membeli, dan loyal pada produk yang ditawarkan perusahaan yang bersangkutan". Hasil penelitian Anissa Faradina (2016) pada pengujian regresi linier berganda menghasilkan bahwa variabel promosi memiliki pengaruh positif serta pada uji hipotesis juga memiliki pengaruh yang signifikan terhadap kepuasan pelanggan. Berdasarkan uraian diatas, maka hipotesis yang dapat diambil dalam penelitian ini adalah,

H4: Promosi berpengaruh positif terhadap kepuasan pelanggan.

\section{Kerangka Pemikiran Empiris}

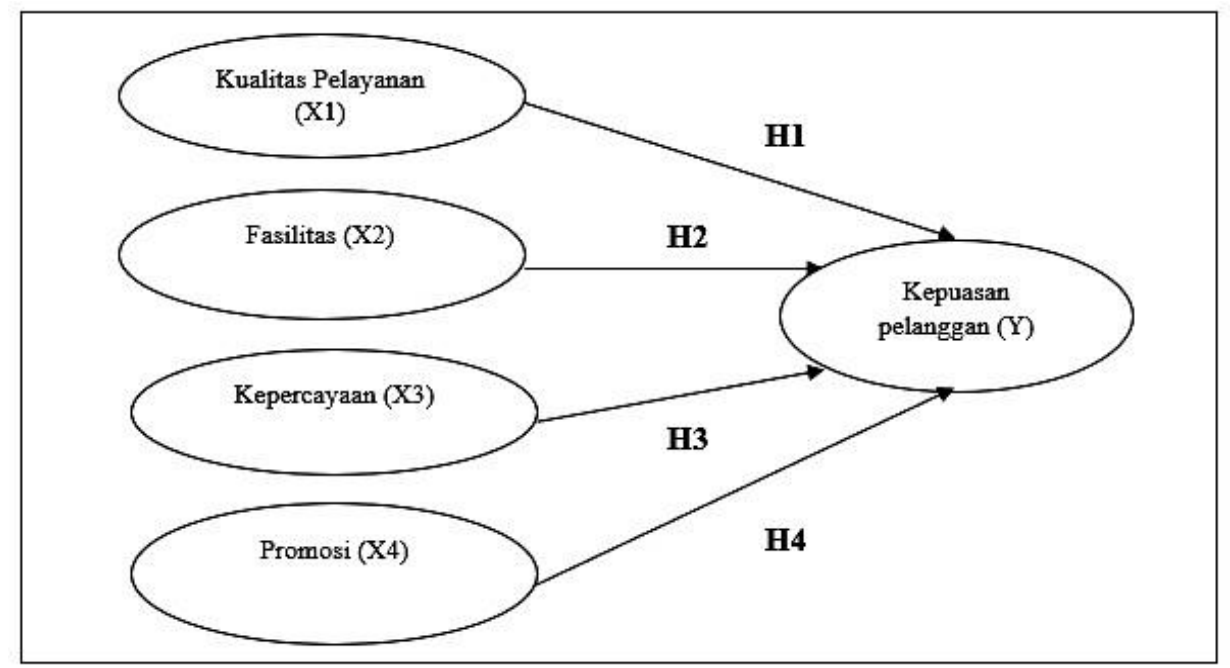




\section{METODE PENELITIAN}

Dalam penelitian ini terdapat dua jenis variabel yaitu variabel independen terdiri dari 4 variabel antara lain Kualitas Pelayanan (X1), Fasilitas (X2), Kepercayaan (X3), dan Promosi (X4) sedangkan variabel dependen dalam penelitian ini adalah Kepuasan Pelanggan (Y).

Populasi dalam penelitian ini adalah seluruh konsumen Hotel Pandanaran Semarang yang tidak diketahui pasti jumlahnya. Teknik sampling yang digunakan adalah teknik sampling non probability sampling dengan jenis purposive sampling (sampel bertujuan) yaitu pemilihan sampel secara subyektif. Pada penelitian ini populasi yang digunakan jumlahnya tidak diketahui secara pasti dan terlalu besar ukurannya, maka menurut (Ferdinand,2013) digunakan rumus :

\section{Keterangan :}

$\mathrm{n} \quad=$ jumlah sampel

$\mathrm{Z}=$ nilai $\mathrm{Z}$ dengan tingkat keyakinan $95 \%$ maka nilai $\mathrm{Z}=1,96$ (tabel distribusi normal)

Moe $=$ margin of error atau kesalahan maksimum $10 \%$

$$
\begin{gathered}
n=\frac{Z^{2}}{4(M o e)^{2}} \\
n=\frac{1,96^{2}}{4(0,1)^{2}} \\
n=\frac{1,96^{2}}{4(0,1)^{2}} \\
n=96
\end{gathered}
$$


Untuk memudahkan penelitian maka jumlah sempel ditetapkan sebanyak 96 orang. Jumlah responden sebanyak 96 orang tersebut dianggap sudah sesuai dari batas minimal sampel. Data yang diperlukan dari dalam penelitian ini adalah data primer. Dimana penelitian ini bersumber dari jawaban langsung responden atas kuisioner yang diajukan. Prinsip pokok teknik analisis kuantitatif adalah mengolah dan menganalisis data-data yang terkumpul menjadi data yang sistematik, terstruktur, teratur, dan mempunyai makna. Analisis yang dilakukan dengan angka - angka dan perhitungannya menggunakan alat bantu statistik yaitu SPSS. Dalam penelitian ini menggunakan SPSS 16, metode analisa yang digunakan yaitu uji validitas, uji reabilitas, uji asumsi klasik : uji normalitas (uji Kolmogorov - smirnov), uji heteroskedastisitas, uji multikolinieritas, Analisis regresi linier berganda.

\section{HASIL PENELITIAN DAN PEMBAHASAN}

Hasil data untuk menguji pengaruh harga, promosi, fasilitas dan lokasi terhadap keputusan menginap pada Hotel Bliss Soetta Semarang, digunakan uji t, asumsinya apabila $\mathrm{t}$ hitung $>$ nilai $\mathrm{t}$ tabel dan nilai Sig, $<\alpha(0,05)$, maka H0 ditolak dan $\mathrm{H} 1$ diterima. Sebaliknya, apabila nilai $\mathrm{t}$ hitung $<$ nilai $\mathrm{t}$ tabel dan nilai Sig, $>\alpha(0,05)$, maka H0 diterima dan $\mathrm{H} 1$ ditolak.

\section{Tabel 2}

\section{Coefficients $^{\mathrm{a}}$}

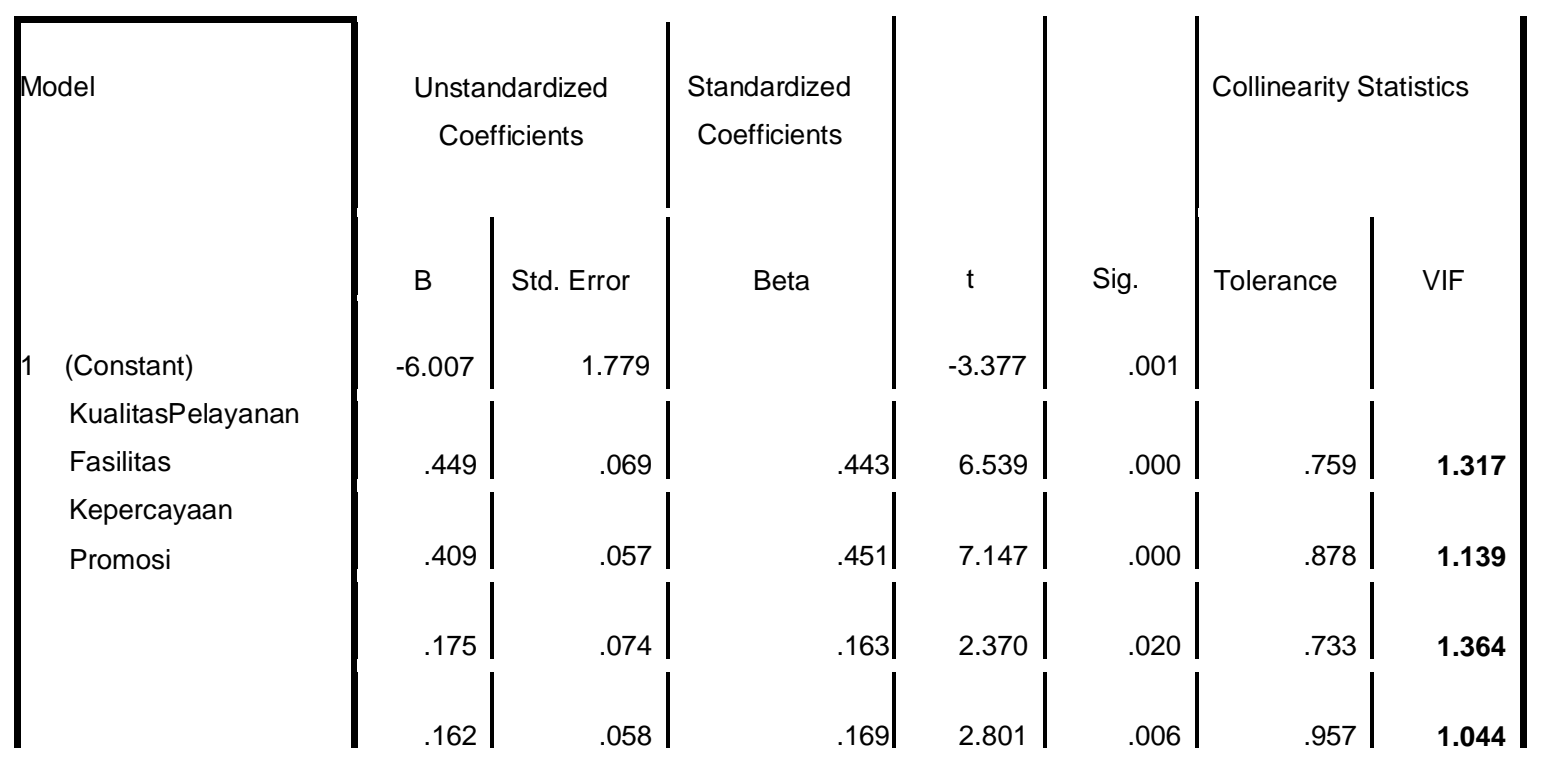




\section{Hasil Uji Linear Berganda}

Hasil penelitian yang telah dilakukan dapat dilihat dalam persamaan berikut :

\section{KepuasanPelanggan = 0,443 Kualitas Pelayanan + 0,451 Fasilitas + 0,163 Kepercayaan + 0,169 Promosi}

a. Hasil $B_{1}$ sebesar positif 0,443 yang berarti apabila kualitas pelayanan ditingkatkan maka kepuasan pelanggan akan semakin meningkat.

b. Hasil $B_{2}$ sebesar positif 0,451 yang berarti apabila fasilitas ditingkatkan maka kepuasan pelanggan akan semakin meningkat.

c. Hasil $\mathrm{B}_{3}$ sebesar positif 0,163 yang berarti apabila kepercayaan ditingkatkan maka kepuasan pelanggan akan semakin meningkat.

d. Hasil $\mathrm{B}_{4}$ sebesar positif 0,169 yang berarti apabila promosi ditingkatkan maka kepuasan pelanggan akan semakin meningkat.

\section{Pengujian Hipotesis}

\section{Uji Hipotesis Kualitas Pelayanan Terhadap Kepuasan Pelanggan}

Hasil pengujian hipotesis 1 diperoleh nilai t-hitung pengaruh kualitas pelayanan terhadap kepuasan pelanggan sebesar 6,539 dan lebih besar dari t-table 1,662 ( $\mathrm{df}=96$ 4) dengan nilai signifikansi hasil sebesar 0,000 lebih kecil dari 0,05. Hasil tersebut menunjukkan bahwa hipotesis 1 dalam penelitian ini diterima, yang artinya bahwa kualitas pelayanan mempunyai pengaruh positif dan signifikan terhadap kepuasan pelanggan.

\section{Uji Hipotesis Fasilitas Terhadap Kepuasan Pelanggan}

Hasil pengujian hipotesis 2 diperoleh nilai thitung pengaruh fasilitas terhadap kepuasan pelanggan sebesar 7,147 dan lebih besar dari $t_{\text {tabel }} 1,662(\mathrm{df}=96-4)$ dengan nilai signifikansi hasil sebesar 0,000 lebih kecil dari 0,05. Hasil tersebut menunjukkan bahwa hipotesis 2 dalam penelitian ini diterima, yang artinya bahwa fasilitas mempunyai pengaruh positif dan signifikan terhadap kepuasan pelanggan.

\section{Uji Hipotesis Kepercayaan Terhadap Kepuasan Pelanggan}

Hasil pengujian hipotesis 3 diperoleh nilai thitung pengaruh kepercayaan terhadap kepuasan pelanggan sebesar 2,370 dan lebih besar dari tabel $1,662(\mathrm{df}=96-4)$ dengan 
nilai signifikansi hasil sebesar 0,020 lebih kecil dari 0,05. Hasil tersebut menunjukkan bahwa hipotesis 3 dalam penelitian ini diterima, yang artinya kepercayaan mempunyai pengaruh positif dan signifikan terhadap kepuasan pelanggan.

\section{Uji Hipotesis Promosi Terhadap Kepuasan Pelanggan}

Hasil pengujian hipotesis 1 diperoleh nilai $t_{\text {hitung }}$ pengaruh promosi terhadap kepuasan pelanggan sebesar 2,801 dan lebih besar dari tabel 1,662 ( $\mathrm{df}=96-4)$ dengan nilai signifikansi hasil sebesar 0,006 lebih kecil dari 0,05. Hasil tersebut menunjukkan bahwa hipotesis 4 dalam penelitian ini diterima, yang artinya promosi mempunyai pengaruh positif dan signifikan terhadap kepuasan pelanggan.

\section{Koefisien Deteterminasi $\left(\mathbf{R}^{2}\right)$}

Tujuan pengujian koefisien determinasi adalah mengukur besarnya kemampuan model persamaan regresi (independen variables) dalam menerangkan variabel terikat.

Tabel 3

Hasil Uji Koefisien Determinasi

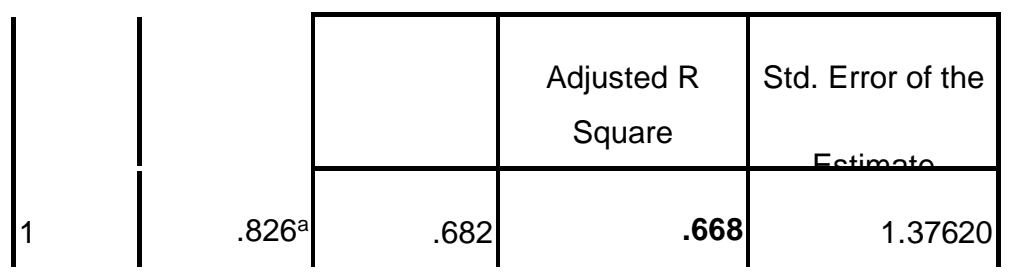

a. Predictors: (Constant), KualitasPelayanan, Fasilitas,

Kepercayaan, Promosi

b. Dependent Variable: KepuasanPelanggan

Sumber : Data primer yang diolah,2019

Tabel tersebut menunjukkan bahwa nilai adjusted $R$ square pada model regresi diperoleh sebesar 0,668 yang artinya 66,8 persen variabel kepuasan pelanggan dapat dijelaskan oleh variabel kualitas pelayanan, fasilitas, kepercayaan dan promosi sedangkan sisanya sebesar 33,2 persen dijelaskan oleh variabel lain diluar penelitian ini. 


\section{KESIMPULAN DAN SARAN}

\section{Kesimpulan}

Hasil penelitian yang telah dilakukan serta hasil pengujian regresi linier berganda penelitian ini menghasilkan, yaitu:

1. Variabel kualitas pelayanan berpengaruh positif dan signifikan terhadap kepuasan pelangan yang berarti apabila kualitas pelayanan ditingkatkan maka akan meningkatkan kepuasan pelanggan.

2. Variabel fasilitas berpengaruh positif dan signifikan terhadap kepuasan pelangan yang berarti apabila fasilitas ditingkatkan maka akan meningkatkan kepuasan pelanggan.

3. Variabel kepercayaan berpengaruh positif dan signifikan terhadap kepuasan pelanggan yang berarti apabila kepercayaan ditingkatkan maka akan meningkatkan kepuasan pelanggan.

4. Variabel promosi berpengaruh positif dan signikfikan terhadap kepuasan pelangan yang berarti apabila promosi ditingkatkan maka akan meningkatkan kepuasanpelanggan.

\section{Saran}

Berdasarkan alat uji analisis diskriptif diketahui masih ada skor terendah pada masing-masing indikator di setiap variabel yang digunakan, maka disarankan untuk Hotel Pandanaran Semarang lebih meningkatkan :

1. Hasil pengujian deskriptif variabel kualitas pelayanan pada indikator bukti fisik mendapatkan skor terendah, disarankan kepada Hotel Pandanaran Semarang untuk mengecuk dan melakukan pergantian secara berkala untuk semua sarana prasarana agar mempermudah aktivitas pelanggan selama tinggal di Hotel Pandanaran Semarang

2. Hasil pengujian deskriptif variabel fasilitas pada indikator kondisi sesuatu ruangan mendapatkan skor terendah disarankan kepada Hotel Pandanaran Semarang dapat lebih menjaga kebersihan dan meningkatkan pengawasan terhadap kinerja karyawan dalam bagian kebersihan area hotel maupun ruangan agar pelanggan tetap merasa nyaman selama tinggal di Hotel Pandanaran Semarang.

3. Hasil pengujian deskriptif variabel kepercayaan pada indikator kompetensi mendapatkan skor terendah disarankan kepada Hotel Pandanaran 
Semarang dapat meningkatkan kualitas karyawan dengan cara memberikan wawasan berupa edukasi dan pelatihan terhadap karyawan dan senantiasa membekali standart operasional prosedur untuk meningkatkan kualitas kompetensi yang dimiliki karyawan agar pelanggan merasa puas dalam pelayanan yang diberikan.

4. Hasil pengujian deskriptif variabel promosi pada indikator hubungan masyarakat mendapatkan skor terendah disarankan kepada Hotel Pandanaran Semarang lebih memperhatikan kegiatan promosi di bidang hubungan masyarakat dengan mengadakan pers, komunikasi perusahan atau mendukung berbagai acara atau event sebagai sponsorship untuk menjaga hubungan yang saling menguntungkan antara perusahaan dan masyarakat yang berpotensi untuk menjadi pelanggan maupun rekan bisnis.

5. Hasil pengujian deskriptif variabel kepuasan pelanggan pada indikator perasaan puas secara keseluruhan mendapatkan skor terendah disarankan kepada Hotel Pandanaran Semarang dapat meningkatkan pelayanan yang prima dan sepenuh hati memahami kebutuhan dan menangani permintaan serta keluhan pelanggan agar harapan pelangan dapat terpenuhi dan meningkatkan kepuasan pelanggan.

\section{REFERENSI}

A, Parasuraman. 2001. The Behaviorial Consequenses of Service Quality. Jurnal of Marketing Vol 60.

Angipora. Marius. P. 1999. Dasar-Dasar Pemasaran. Jakarta: PT Raja Grafindo Persada.

Augusty, Ferdinand. 2013. Metode Penelitian Manajemen. Semarang: Penerbit Universitas Diponegoro.

Barnes, James G. 2003. Secrets Of Customer Relationship Management. Yogyakarta: Andi.

Bashu Swastha, Irwan. 1997. Manajemen Pemasaran Modern. Yogyakarta: Liberty Offset.

Faradina, Anissa dan Budhi Satrio. 2016. "Pengaruh Promosi dan Kualitas Pelayanan terhadap Kepuasan Pelanggan Pada Rumah Cantik Alamanda." Jurnal Ilmu dan Riset Manajemen Vol.5 No.7.

Karsono. 2006. Pemikiran - Pemikiran Dalam Pembangunan Kesejahteraan Sosial. Jakarta: Lembaga Penerbit FE-UI. 
Kesuma, Eka, Amri dan M. Shabri. 2015. "Pengaruh Kualitas Pelayanan dan Kpercayaan Terhadap Kepuasan Pelanggan Pada Sulthan Hotel Banda Aceh." Jurnal manajemen pascasarjana Universitas Syiah Kuala Bol.4 No.4.

Khasanah, Imroatul. 2015. “Analisis Pengaruh Nilai Pelanggan, Experiental Marketing dan Rasa Kepercayaan Terhadap Kepuasan Pelanggan (Studi Kasus Hotel Pondok Tingal Magelang).” Jurnal Studi Manajemen \& Organisasi 12.

Kotler, P dan Amstrong, G. 2008. Bauran pemasaran Edisi ke-12 Jilid 2. Jakarta: Erlangga.

—. 2001. PrinsipPrinsip Pemasaran, Edisi Kedelapan, Jilid. 1. Jakarta: Erlangga.

Lupiyoadi, Rambat. 2001. Manajemen Pemasara Jasa: Berbasis Kompetensi.

Jakarta:

Salemba Empat.

—. 2006. Manajemen Pemasaran Jasa Edisi Revisi. Jakarta: Salemba Empat. Nirwana. 2004. Prinsip-Prinsip Pemasaran Jasa. Malang: Dioma.

Notoatmodjo, Soekidjo. 2005. Metodologi Penelitian Kesehatan. Jakarta: Rineka Cipta.

Prasetyo, Aryo dan Imroatul khasanah. 2015. "Analisis Pengaruh Kualitas Pelayanan, Harga dan Fasilitas Terhadap Kepuasan Pelanggan Hotel Pondok Tingal di Kbupaten Magelang.” Diponegoro Journal of Management Vol.4 No.3.

Raharjani, Jeni. 2005. “Analisis Faktor-faktor yang Mempengaruhi Keputusan Pemilihan Pasar Swalayan Sebagai Tempat Berbelanja (Studi Kasus pada Pasar Swalayan di Kawasan Seputar Simpang Lima Semarang)." Jurnal Studi Manajemen dan Organisasi, Vol.2, No.1.

Soekanto, Soerjono. 1995. Sosiologi Suatu Pengantar. Jakarta: PT Raja Grafindo.

Sugiyono. 2013. Metode Penelitian Pendidikan Pendekatan Kuantitatif, Kualitatif, dan $R \& D$. Bandung: Alfabeta.

Supranto. 2001. Pengukuran Tingkat Kepuasan Pelanggan Untuk Menaikkan Pangsa Pasar. Jakarta: Rineka Cipta.

Tjiptono, Fandy. 2006. Manajemen Pelayanan Jasa. Yogyakarta: Andi.

Wilkie, William L. 1994. Consumer Behavior. New York: Third Edition, Jhon Wiley \& Sons Inc. 